\title{
Diagnosis of vibriosis in the era of genomics: lessons from invertebrates
}

\author{
Le Roux Frederique ${ }^{1,2,{ }^{*}}$
}

${ }^{1}$ IFREMER, Unite Physiol Fonct Organismes Marins, ZI Pointe Diable, CS 10070, F-29280 Plouzane, France.

${ }^{2}$ Univ Paris 06, Univ Paris 04, CNRS,UMR 8227,CS 90074, Integrat Biol Marine Models,Stn Biol Roscoff, F-29688 Roscoff, France.

* Corresponding author : Frédérique Le Roux, email address : fleroux@sb-roscoff.fr

\begin{abstract}
:
Global changes linked to increases in temperature and ocean acidification, but also to more direct anthropogenic influences such as aquaculture, have caused a worldwide increase in the reports of Vibrio-associated illnesses affecting humans and also animals such as shrimp and molluscs. Investigation of the emergence of Vibrio pathogenesis events requires the analysis of microbial evolution at the gene, genome and population levels, in order to identify genomic modifications linked to increased virulence, resistance and/or prevalence, or to recent host shift. From a more applied point of view, the elucidation of virulence mechanisms is a prerequisite to devising prophylactic methods to fight infectious agents. In comparison with human pathogens, fairly little is known about the requirements for virulence in vibrios pathogenic to animals. However, the advent of genome sequencing, especially nextgeneration technologies, the possibility of genetically manipulating most of the Vibrio strains, and the recent availability of standardised animals for experimental infections have now compensated for the considerable delay in advancement of the knowledge of non-model pathogens such as Vibrio and have led to new scientific questions.
\end{abstract}

Keywords : Ecology, Emergence, Evolution, Marine invertebrate, Vibriosis, Virulence 
Increase in sea surface temperature and ocean acidification linked to global change and human activities such as aquaculture, have caused a worldwide increase in the reports of Vibrio-associated diseases, with ecosystem-wide direct and indirect effects on humans and marine animals (For a review see 1). In Europe, several studies have reported the presence of human pathogens (e.g., V. parahaemolyticus, V. cholerae non-O1/non-O139) in shellfish as well as in coastal and estuarine waters (2-16). Several lines of evidences suggest that these infections are increasing and tend to follow regional climatic trends with outbreaks typically following episodes of unusually warm weather. In northern Europe, the salmonid farming industry is constantly threatened by pathogens, such as Vibrio salmonicida and $V$. anguillarum (17). In France, several Vibrio species have been associated with recent and massive losses in the oyster industry $(18,20)$. In Spain Photobacterium damselae is associated with diseases of cultured fish species (20) and $V$. vulnificus with hemorrhagic septicaemia in eels (21). Both fish pathogens deserve special attention since they are able to cause septicemia in humans. Finally, evidence has also been gathered linking Vibrio infections (e.g. Vibrio coralliilyticus) to increasing mass mortality of benthic corals (e.g. Paramuricea clavata) in the NW Mediterranean Sea (22). In this context, the development of operational tools to identify and detect emergent pathogens is essential to zoosanitary monitoring of cultivated species as well as to inform and enhance studies on wild animal populations.

\section{Experimental challenge still remains the only way to determine the virulence of an isolate}

Vibrio infections of invertebrates are widely documented (for review see 23). However, compared to human pathogens, little is known regarding the mode of pathogenesis. More often, the virulence of a given strain must be assessed by experimental challenge. However, analysis of the data generated by this approach is hampered by the variability of the physiological state and a heterogeneous genetic background of the animals, combined with a continuously changing environment (food, temperature, salinity, pollutants). Even more disturbing is the fact that invertebrate tissues naturally housing bacteria that can lead to misinterpretations of obtained results (24).

The use of gnotobiotic systems (i.e. animals cultured in axenic conditions or with a known microflora) is a promising tool to diagnose pathogenic strains and extend our understanding of the mechanisms involved in host-microbe interactions (for review see 25). Most studies performed so far have used axenic Artemia fransciscana as a test organism. This system has allowed for the investigation of several aspects of crustacean-Vibrio interactions, such as colonization (of pathogenic or probiotic isolates), biofilm formation, toxicity of exoenzymes, and infection route (26-29). However as a heterologous system, this model may exclude species-specific pathogens and specific virulence mechanisms.

Experimental challenge in larvae seems to give reproducible results, and as a consequence, the pathogenic status of tested strains is less controversial than in adult animals (30). Generally, bacterial isolates are incubated directly with larval cultures and mortalities appear rapidly, i.e. from 1-10 days after infection. These tests can be miniaturized and therefore permit the screening of large numbers of isolates. However, because several strains are pathogenic only from certain developmental stages (for example Vibrio penaeicida in the shimp Litopenaeus stylirostris, see 31), this procedure cannot be used as a broad test for virulence. 
Putative pathogens are frequently selected by injection of bacterial suspensions in the animals The results are obtained quickly since mortality often appears in a few days. The recent development of specific-pathogen-free (SPF) and standardized spats of Crassostrea gigas (32, 33) has made high-throughput screening of oyster pathogenic isolates by injection possible $(18,19)$. However, injection techniques do not reflect the natural route of infection, thus precluding other factors (e.g. chemotaxis, colonisation etc.) that may be involved in the infection process (Figure 1). Furthermore, these laboratory analyses do not capture the complexity of infection occurring in the natural environment. For instance, oysters are typically injected with a single bacterial strain, whereas in the environment, animals are typically colonized by a diverse assemblage of Vibrio species $(19,30)$.

Experimental infection by immersion has gained success in demonstrating the virulence of some Vibrio strains towards shrimp (34), oyster (35) clam (36) and octopus (37). However, this method frequently does not result in any mortality at all. This lack of reproducibility may be due to the fact that the ability of vibrios to induce disease in the wild may depend on associations with other bacteria or attachment to other organisms and particles. For instance, a recent study has reported that marine aggregates facilitate retention of nanoparticles (including bacteria) by suspension-feeding bivalves (38). Thus, monitoring of animals in an environment in which bacteria are not simply in a planktonic form may yield a more accurate understanding of the factors that contribute to virulence. Identifying the microhabitats of pathogens (39) may facilitate further development of an experimental infection model representative of the natural route of infection (e.g. through the use of adapted polymeric substrates and or cellular vectors). Such an approach would also allow for a better understanding of the mode of transmission and primary target tissues or organs for these pathogens.

The lack of knowledge concerning the vibrio pathogenesis in marine animals is in part a consequence of the absence of standardized models for in vivo studies. Indeed, with no inbred animal lines, the genetic background of the experimental animals is heterogeneous. Furthermore as bacteria naturally infect invertebrates, the diversity of the natural microflora may also contribute to a lack of reproducibility. Of the recent work aiming to improve the in vivo model, the standardization of animal hatching and attempts to mimic the natural route of infection determination seem to have the most promising perspectives.

\section{Cellular and/or molecular tests to evaluate potential virulence}

In light of the difficulties faced by current techniques of experimental infection in nondomesticated animals, the development of cellular and/or molecular tests to evaluate the potential virulence of strains is necessary. The development of such bioassays could be informed by descriptions of host alterations to define the virulence mechanisms involved in pathogenesis. However, in these systems, it is difficult to establish a specific clinical table of disease characteristics for four main reasons: 1) it is necessary to analyze a high number of samples to investigate any one specific observation; 2) the absence of external symptoms frequently leads to the observation/description of post-mortem lesions; 3) the size of the pathogen is inhibitory to detection; and 4) invertebrates are already colonized by commensal community of microbes. Thus, specific molecular tools, such as in situ hybridization and fluorescent-labeled bacteria, should be developed to describe the infection route and eventual specific localization and migrations of Vibrio pathogens. GFP-labeled Vibrio have already been used to investigate Vibrio-invertebrate interactions at both organismal and cellular levels (Figure 2) (40-42). 
Standardized in vitro assays are also necessary to screen for distinct activities covered by the generic term virulence, such as adherence and cytolytic effects. As marine invertebrate cell lines are not yet available, experiments aiming to understand interactions between host cells and pathogenic Vibrios have thus far relied mainly on primary lines of hemocytes $(41,43)$. However, the use of such a cell population has drawbacks. The hemocyte population is made of distinct cell types that have yet to be fully characterized. Moreover, each animal provides a limited number of cells (about $10^{6}$ ), and experiments using this hemocyte procedure would require the pooling of hemocytes from different individuals with heterogeneous genetic backgrounds in order to achieve the required sample size. Additionally, during an experiment of sufficient duration, bacteria that naturally occur in the hemolymph will proliferate. Interestingly, a recent report has described the use of primary cell cultures from abalone gills to investigate the $V$. harveyi-abalone interaction (44). Also, heterologous cell lines, such as Bge (mollusk from fresh water) or NIH3T3 (mouse fibroblastic cell lines), have been used to describe the cytopathic effects of a metalloprotease expressed by an oyster pathogen (45). However, due to osmolarity restrictions, such an approach is still limited to extracellular product analyses.

Bacterial pathogenicity is known to be associated with the structural components of the cells (e.g. capsules, fimbriae, LPS, endotoxins, and other cell wall components), or with the active secretion of substances that either damage host tissues or protect the bacteria against host defenses (invasin enzymes, hemolysin, coagulase, toxins). Several virulence factors have already been identified in Vibrio pathogenic to invertebrates. A metalloprotease has been demonstrated to be a key factor in the extracellular product (ECP) toxicity in $V$. splendidus (46) V. aestuarianus (43)V. tubiashi (47) and V. corallyliticus (48). The porin OmpU was reported to be an essential virulence factor in the $V$. splendidus-Crassostrea gigas interaction (49). More recently, a serine protease was found to be specifically secreted through outer membrane vesicles (OMVs) and shown to participate in the virulence of a $V$. splendidusrelated strain (50). Dj1A, an inner membrane co-chaperone belonging to the DnaJ family, was shown to be necessary for cytotoxicity of the clam pathogen $V$. tapetis to hemocytes (51). Additionally, from the genomic identification of homologues of genes involved in virulence in other bacterial pathogens, several putative virulence factors have been identified (52). These include potential toxins such as hemolysins, MARTX, proteases, a type VI secretion system, adhesins, as well as genes for siderophore production, transport and utilization. A caveat of this analysis is that the majority of these homologues has been identified on the basis of vertebrate pathogen studies, possibly precluding the discovery of new mechanisms specific to invertebrate pathogens. Furthermore the knowledge of the absence/presence/diversity of these genes does not appear sufficient for the determination of a strain's pathogenicity.

These last few years, few likely virulence mechanisms of vibrios pathogenic for invertebrates have been described at the cellular and molecular level, leading to a better understanding of some pathogenic effects. However to date, detection of these genes is not sufficient to conclude about the pathogenicity of the strain. Microbial pathogenesis is often multifactorial, and pathogens use several biochemical mechanisms operating in concert to produce infections and diseases. In addition, intra and inter-species diversity in virulence mechanisms complicates the development of diagnostic tools to determine the pathogenicity of the strain.

\section{Genome sequence and typing virulent strains}

Due to the lack of knowledge of marine bacterial virulence mechanisms and diversity, a "blind" approach has been necessarily employed in order to correlate a genotype (or a group 
of related genotypes) with virulence potential. In the last few years, significant progress has been made in understanding the population structure and diversity of the Vibrio (53). Despite their enormous microdiversity, these organisms fall into well-defined genetic clusters that have similar resource preferences. These clusters have been hypothesized to correspond to populations that act as cohesive ecological units, i.e. ecological populations (39). However, a link between ecological populations and pathogenicity has not been demonstrated, and it is unclear whether pathogenicity is a trait primarily linked to clones, or to populations comprising a large number of distinct genotypes.

Combining experimental ecology, a high throughput infection assay, and genome sequencing, we were recently able to show that Vibrio pathogenicity for oyster spat in France can be ascribed to a cluster of genetically related strains that coincides with a previously defined ecologically cohesive population and to the $V$. crassostreae species delineation (19). Despite a strong clonal frame in the core genome (genes shared by all the strains of the population), the flexible genome was highly diverse with 100-1200 strain specific genes. Genes specific to this population likely reflect the selective pressure associated with population specialization, and we have demonstrated that one of these genes is required for pathogenicity. Thus, in the case of the $V$. crassostreae infection, the functional unit of virulence is the population (or species) and diagnostic tools can be based on taxonomic markers polymorphisms or population specific gene detection (Figure 3).

The genome based phylogeny of $V$. aestuarianus related strains shows that the isolates infecting diseased oysters are clustered into two specific lineages (18). These lineages contain a large majority of the virulent strains. The strong clonal frame in the core genome and absence of strain specific genes within the lineages led us to hypothesize that the common ancestor was pathogenic and that a few modern strains have lost some key virulence factor(s). This has been recently illustrated by the identification of a frameshift in a non-virulent strain, in a gene coding for a histidine kinase (VarS). A knock out of this gene in a virulent strain confirmed its role as a regulator for $V$. aestuarianus virulence. Thus, in the case of $V$. aestuarianus, the functional unit of virulence is the lineage, probably as a consequence of the clonal expansion of a virulent strain (Figure 3). The diagnosis should map taxonomic markers as soon as it leads to the discrimination of the lineage within the species.

The population structure of Vibrio nigripulchritudo related strains highlights a high genetic diversity (54). However virulent strains associated to shrimp disease are found exclusively in specific lineages. Within each lineage, the strains are nearly clonal but only some of them are virulent. Complete sequencing and comparative genome analysis demonstrated that the virulent strains contain specific mobile genetic elements further reported to be necessary for virulence. These elements are different between virulent strains from each lineage but a single toxin is shared by all of them. Thus, in the case of $V$. nigripulchritudo, the functional unit is the strain within lineage and the diagnosis should map the toxin (Figure 3).

To summarize, we have illustrated here the difficulty in developing diagnostic tools based on genotyping methods resulting from the diversity of pathogen evolutionary scenarios within the Vibrios. In some cases, pathogens arise from the clonal expansion of a strain via lateral gene transfer. In other cases, virulence seems to be linked to the differentiation of ecological populations or species. It should be noted that none of these data would have been obtained from single gene (more often $16 \mathrm{~S}$ analyses) which is unfortunately still being used to identify "putative" pathogens in aquaculture. 
With the revolution of high throughput technologies, it is now possible to sequence a large collection of genomes, perform population structure analyses at the genome scale, and investigate the functional unit of virulence for each putative pathogen. In addition, comparing

the genome of virulent strains or populations with their closest non-virulent phylogenetic neighbors will lead to the identification of virulence markers. Then, genetic analyses will highlight the genes that are necessary for infection - a prerequisite to developing cellular and/or molecular tests to diagnose pathogenicity.

\section{Metagenomic and exploring a polymicrobial disease}

Marine invertebrates house abundant communities of microbes, which are increasingly recognized to influence the health of these animals. This association can be beneficial as some microbes provide additional energy sources to the host or prevent the establishment of pathogens. For instance, a recent study showed that about 3\% of oyster haemolymphassociated cultivable bacteria displayed antibacterial activity toward vibrio (55). Using a metabarcoding approach, Wegner and coll showed in oyster that microbial communities are stable over time and assemble in a animal's genotype specific manner. However a change of the environment, such as temperature stress, can disrupt such associations and promote dominance of opportunists (56).

In addition two studies support the hypothesis of increased virulence due to microbe interaction in oysters. First, experimental infections have demonstrated that some Vibrio strains are moderately virulent when injected into animals individually, and display heightened virulence in mixed experimental infections (57). Second, the analyses of oyster mortality following experimental infection suggest that disease onset can be facilitated by the presence of non-virulent strains (19). Hence although non-virulent strains are not sufficient for pathogenesis, they clearly have some features (as yet undetermined) that contribute either directly or indirectly to pathogenicity mechanisms. One possibility is that non-virulent strains provide resources required by the virulent strains, acting as "cheaters". This phenomenon has been seen in some analyses of siderophore synthesis and utilization (58). An alternate role for the non-virulent strains may be to generate a sufficient bacterial load, either to overcome host defenses or to induce expression of virulence factors that are regulated by quorum sensing (59).

Therefore in the future, the investigation of vibrio pathogenicity for oyster, as for other marine invertebrates, should incorporate metagenomic analysis on the whole microbial community. This approach should lead to correlate spatio-temporal dynamic of populations with cooperative behavior (e.g. quorum sensing, public good) and weapon sharing (e.g. synergic/additional virulence traits; lateral gene transfer).

\section{Acknowledgements}

I warmly thank Teagan Mayer (Rebecca Case lab, University of Alberta, Canada) and Dr Yannick Labreuche for critically reading the manuscript and for their help in editing the English language. This work was supported in part by grants from the ANR (11-BSV7-023$01 «$ VIBRIOGEN » and 13-ADAP-0007-01« OPOPOP»). 


\section{References}

1. Le Roux F., Wegner M., Baker-Austin C., Vezzulli L., Carlos R. Osorio C.R., Amaro C., Ritchie J.M., Defoirdt T., Destoumieux-Garzón D., Blokesch M., Mazel D., Jacq A., Cava F., Gram G., Wendling C.C., Strauch E., KirschnerA., Huehn S. The Emergence of Vibrio pathogens in Europe: Ecology, Evolution and Pathogenesis (Paris, 11-12 March 2015). Submit in Frontiers in Microbiology.

2. Igbinosa, E.O., \& Okoh, A.I. (2008). Emerging Vibrio species: an unending threat to public health in developing countries. Res Microbiol 159, 495-506.

3. Baker-Austin, C., Trinanes, J.A., Taylor, N.G.H., Hartnell, R., Siitonen, A., \& Martinez-Urtaza, J. (2013). Emerging Vibrio risk at high latitudes in response to ocean warming. Nature Climate Change 3, 73-77.

4. Huehn, S., Eichhorn, C., Urmersbach, S., Breidenbach, J., Bechlars, S., Bier, N., Alter, T., Bartelt, E., Frank, C., Oberheitmann, B., Gunzer, F., Brennholt, N., Boer, S., Appel, B., Dieckmann, R., \& Strauch, E. (2014). Pathogenic vibrios in environmental, seafood and clinical sources in Germany. Int J Med Microbiol 304, 843-850.

5. Andersson, Y., \& Ekdahl, K. (2006). Wound infections due to Vibrio cholerae in Sweden after swimming in the Baltic Sea, summer 2006. Euro Surveill 11, E060803 060802 .

6. Lukinmaa, S., Mattila, K., Lehtinen, V., Hakkinen, M., Koskela, M., \& Siitonen, A. (2006). Territorial waters of the Baltic Sea as a source of infections caused by Vibrio cholerae non-O1, non-O139: report of 3 hospitalized cases. Diagn Microbiol Infect Dis 54, 1-6.

7. Dalsgaard, A., Frimodt-Moller, N., Bruun, B., Hoi, L., \& Larsen, J.L. (1996). Clinical manifestations and molecular epidemiology of Vibrio vulnificus infections in Denmark. Eur J Clin Microbiol Infect Dis 15, 227-232.

8. Stypulkowska-Misiurewicz, H., Pancer, K., \& Roszkowiak, A. (2006). Two unrelated cases of septicaemia due to Vibrio cholerae non-O1, non-O139 in Poland, July and August 2006. Euro Surveill 11, E061130 061132.

9. Reilly, G.D., Reilly, C.A., Smith, E.G., \& Baker-Austin, C. (2011). Vibrio alginolyticus-associated wound infection acquired in British waters, Guernsey, July 2011. Euro Surveill 16.

10. Cantet F., Hervio-Heath D., Caro A., Le Mennec C., Monteil C., Quéméré C., JolivetGougeon A., Colwell R.R. \& Monfort P. (2013) Quantification of Vibrio parahaemolyticus, Vibrio vulnificus and Vibrio cholerae in French Mediterranean coastal lagoons. Res Microbiol. 164 (8):867-74.

11. Schets, C. (2012). "Pathogenic Vibrio spp. in Northern European Waters", in: International Symposium, 31 May - 1 June 2012 in Koblenz. (ed.) B.F. Gewässerkunde. (Koblenz: Bundesministerium für Verkehr, Bau und Stadtentwicklung).

12. Bisharat, N., Agmon, V., Finkelstein, R., Raz, R., Ben-Dror, G., Lerner, L., Soboh, S., Colodner, R., Cameron, D.N., Wykstra, D.L., Swerdlow, D.L., \& Farmer, J.J., 3rd (1999). Clinical, epidemiological, and microbiological features of Vibrio vulnificus biogroup 3 causing outbreaks of wound infection and bacteraemia in Israel. Israel Vibrio Study Group. Lancet 354, 1421-1424.

13. Torres, L., Escobar, S., Lopez, A.I., Marco, M.L., \& Pobo, V. (2002). Wound Infection due to Vibrio vulnificus in Spain. Eur J Clin Microbiol Infect Dis 21, 537538. doi: 10.1007/s10096-002-0767-4.

14. Partridge, D.G., Townsend, R., Larkin, S., \& Parsons, H.K. (2009). Vibrio vulnificus: an unusual mode of acquisition and novel use of rapid susceptibility testing. J Clin Pathol 62, 370-372. 
15. Huhulescu, S., Indra, A., Feierl, G., Stoeger, A., Ruppitsch, W., Sarkar, B., \& Allerberger, F. (2007). Occurrence of Vibrio cholerae serogroups other than O1 and O139 in Austria. Wien Klin Wochenschr 119, 235-241.

16. Kirschner, A.K., Schlesinger, J., Farnleitner, A.H., Hornek, R., Suss, B., Golda, B., Herzig, A., and Reitner, B. (2008). Rapid growth of planktonic Vibrio cholerae nonO1/non-O139 strains in a large alkaline lake in Austria: dependence on temperature and dissolved organic carbon quality. Appl Environ Microbiol 74, 2004-2015.

17. Austin, B. (2011). Taxonomy of bacterial fish pathogens. Vet Res 42, 20.

18. Goudenege, D., Travers, M.A., Lemire, A., Petton, B., Haffner, P., Labreuche, Y., Tourbiez, D., Mangenot, S., Calteau, A., Mazel, D., Nicolas, J.L., Jacq, A., and Le Roux, F. (2014). A single regulatory gene is sufficient to alter Vibrio aestuarianus pathogenicity in oysters. Environ Microbiol. doi: 10.1111/1462-2920.12699.

19. Lemire, A., Goudenege, D., Versigny, T., Petton, B., Calteau, A., Labreuche, Y., \& Le Roux, F. (2014). Populations, not clones, are the unit of vibrio pathogenesis in naturally infected oysters. ISME J. doi: 10.1038/ismej.2014.233.

20. Fouz, B., Larsen, J.L., Nielsen, B., Barja, J.L., \& Toranzo, A.E. (1992). Characterization of Vibrio damsela strains from turbot Scophthalmus maximus in Spain. Diseases of Aquatic Organisms 12, 155-166.

21. Haenen, O.L., Evans, J.J., \& Berthe, F. (2013). Bacterial infections from aquatic species: potential for and prevention of contact zoonoses. Rev Sci Tech 32, 497-507.

22. Vezzulli, L., Previati, M., Pruzzo, C., Marchese, A., Bourne, D.G., \& Cerrano, C. (2010). Vibrio infections triggering mass mortality events in a warming Mediterranean Sea. Environ Microbiol 12, 2007-2019.

23. Thompson, F.L., Iida, T., \& Swings, J. (2004). Biodiversity of vibrios. Microbiol Mol Biol Rev 68, 403-431.

24. Pruzzo, C., Gallo, G. \& Canesi, L. (2005) Persistence of vibrios in marine bivalves: the role of interactions with haemolymph components. Environ Microbiol. 7(6):76172 .

25. Marques, A., Ollevier, F., Verstraete, W., Sorgeloos, P., \& Bossier, P. (2006). Gnotobiotically grown aquatic animals: opportunities to investigate host-microbe interactions. Journal of applied microbiology 100, 903-918.

26. Defoirdt, T. (2013). Antivirulence therapy for animal production: filling an arsenal with novel weapons for sustainable disease control. PLoS Pathog 9, e1003603. doi: 10.1371/journal.ppat.1003603.

27. Defoirdt, T., Bossier, P., Sorgeloos, P., \& Verstraete, W. (2005). The impact of mutations in the quorum sensing systems of Aeromonas hydrophila, Vibrio anguillarum and Vibrio harveyi on their virulence towards gnotobiotically cultured Artemia franciscana. Environ Microbiol 7, 1239-1247.

28. Defoirdt, T., Darshanee Ruwandeepika, H.A., Karunasagar, I., Boon, N., \& Bossier, P. (2010). Quorum sensing negatively regulates chitinase in Vibrio harveyi. Environ Microbiol Rep 2, 44-49.

29. Defoirdt, T., \& Sorgeloos, P. (2012). Monitoring of Vibrio harveyi quorum sensing activity in real time during infection of brine shrimp larvae. ISME J 6, 2314-2319.

30. Wendling, C.C., Batista, F.M., \& Wegner, K.M. (2014). Persistence, seasonal dynamics and pathogenic potential of Vibrio communities from Pacific oyster hemolymph. PLoS One 9, e94256. doi: 10.1371/journal.pone.0094256.

31. Goarant, C., Merien, F., Berthe, F., Mermoud, I. \& Perolat P. (1999) Arbitrarily primed PCR to type Vibrio spp. pathogenic for shrimp. Appl Environ Microbiol. 65(3):1145-51. 
32. Petton, B., Pernet, F., Robert, R., \& Boudry, P. (2013). Temperature influence on pathogen transmission and subsequent mortalities in juvenile Pacific oysters Crassostrea gigas. Aquacult Environ Interact 3, 257-273.

33. Petton, B., Boudry P. \& Pernet F. (2015). Factors influencing disease-induced mortality of Pacific oysters Crassostrea gigas. Aquaculture Env Interact 6, 205-222.

34. Le Roux, F., Labreuche, Y., Davis, B.M., Iqbal, N., Mangenot, S., Goarant, C. Mazel, D.\& Waldor, M.K. (2011). Virulence of an emerging pathogenic lineage of Vibrio nigripulchritudo is dependent on two plasmids. Environmental microbiology 13: 296306.

35. Waechter, M., Le Roux, F., Nicolas, J.L., Marissal, E. \& Berthe, F. (2002). Characterisation of Crassostrea gigas spat pathogenic bacteria. C R Acad Sc 325: 231238.

36. Gomez-Leon, J., Villamil, L., Lemos, M.L., Novoa, B. \& Figueras, A. (2005). Isolation of Vibrio alginolyticus and Vibrio splendidus from aquacultured carpet shell clam (Ruditapes decussatus) larvae associated with mass mortalities. Appl Environ Microbiol. 71:98-104.

37. Farto, R., Armada, S.P., Montes, M., Guisande, J.A., Perez, M.J. \& Nieto, T.P. (2003). Vibrio lentus associated with diseased wild octopus (Octopus vulgaris). $J$ Invertebr Pathol 83:149-56.

38. Froelich, B., Ayrapetyan, M. \& Oliver, J.D. (2012). Vibrio vulnificus integration into marine aggregates and subsequent uptake by the oyster, Crassostrea virginica. Appl Environ Microbiol. 79:1454-8.

39. Hunt, D.E., David, L.A., Gevers, D., Preheim, S.P., Alm, E.J. \& Polz, M.F. (2008). Resource partitioning and sympatric differentiation among closely related bacterioplankton. Science 320: 1081-1085.

40. Travers, M.A., Barbou, A., Le Goïc, N., Huchette, S., Paillard, C. \& Koken M. (2008) Construction of a stable GFP-tagged Vibrio harveyi strain for bacterial dynamics analysis of abalone infection. FEMS Microbiol Lett. 289(1):34-40.

41. Duperthuy, M., Schmitt, P., Garzon, E., Caro, A., Rosa, R.D., Le Roux, F. et al (2011). Use of OmpU porins for attachment and invasion of Crassostrea gigas immune cells by the oyster pathogen Vibrio splendidus. Proc Natl Acad Sci U S A 108: 2993-2998.

42. Goulden, E.F., Hall, M.R., Bourne, D.G., Pereg, L.L. \& Høj, L. (2012) Pathogenicity and infection cycle of Vibrio owensii in larviculture of the ornate spiny lobster (Panulirus ornatus). Appl Environ Microbiol. 78(8):2841-9.

43. Labreuche, Y., Le Roux, F., Henry, J., Zatylny, C., Huvet, A., Lambert, C. et al (2010). Vibrio aestuarianus zinc metalloprotease causes lethality in the Pacific oyster Crassostrea gigas and impairs the host cellular immune defenses. Fish Shellfish Immunol 29: 753-758.

44. Pichon D, Cudennec B, Huchette S, Djediat C, Renault T, Paillard C \&AuzouxBordenave S. (2013) Characterization of abalone Haliotis tuberculata-Vibrio harveyi interactions in gill primary cultures. Cytotechnology. 65(5):759-72.

45. Binesse, J., Delsert, C., Saulnier, D., Champomier-Vergès, M.C., Zagorec, M., Munier-Lehmann, H., Mazel, D. \& Le Roux, F. (2008) Metalloprotease vsm is the major determinant of toxicity for extracellular products of Vibrio splendidus. Appl Environ Microbiol. 74(23):7108-17.

46. Le Roux, F., Binesse, J., Saulnier, D. \& Mazel, D. (2007) Construction of a Vibrio splendidus mutant lacking the metalloprotease gene vsm by use of a novel counterselectable suicide vector. Appl Environ Microbiol. 73(3):777-84.

47. Hasegawa, H. \& Häse C.C. (2009) The extracellular metalloprotease of Vibrio tubiashii directly inhibits its extracellular haemolysin. Microbiology. 155 : 2296-305. 
48. Santos Ede, O., Alves, N., Dias, G.M., Mazotto, A.M., Vermelho, A., Vora, G.J., Wilson, B., Beltran, V.H., Bourne, D.G., Le Roux, F. \& Thompson, F.L. (2011) Genomic and proteomic analyses of the coral pathogen Vibrio coralliilyticus reveal a diverse virulence repertoire. ISME J. 5(9):1471-83.

49. Duperthuy, M., Binesse, J., Le Roux, F., Romestand, B., Caro, A., Got, P., Givaudan, A., Mazel, D., Bachère, E. \& Destoumieux-Garzón, D. (2010) The major outer membrane protein OmpU of Vibrio splendidus contributes to host antimicrobial peptide resistance and is required for virulence in the oyster Crassostrea gigas. Environ Microbiol. 12(4):951-63.

50. Vanhove, A.S., Duperthuy, M., Charrière, G.M., Le Roux, F., Goudenège, D., Gourbal, B., Kieffer-Jaquinod, S., Couté, Y., Wai, S.N. \& Destoumieux-Garzón, D. (2014) Outer membrane vesicles are vehicles for the delivery of Vibrio tasmaniensis virulence factors to oyster immune cells. Environ Microbiol. Jun 11. doi: 10.1111/1462-2920.12535

51. Lakhal F, Bury-Moné S, Nomane Y, Le Goïc N, Paillard C, Jacq A. (2008) DjlA, a membrane-anchored DnaJ-like protein, is required for cytotoxicity of clam pathogen Vibrio tapetis to hemocytes. Appl Environ Microbiol. 74(18):5750-8

52. Le Roux, F., Zouine, M., Chakroun, N., Binesse, J., Saulnier, D., Bouchier, C., Zidane, N., Ma, L., Rusniok, C., Lajus, A., Buchrieser, C., Médigue, C., Polz, M.F. \& Mazel D. (2009) Genome sequence of Vibrio splendidus: an abundant planctonic marine species with a large genotypic diversity. Environ Microbiol. 11(8):1959-70.

53. Thompson, J.R., Pacocha, S., Pharino, C., Klepac-Ceraj, V., Hunt, D.E., Benoit J et al (2005). Genotypic diversity within a natural coastal bacterioplankton population. Science 307: 1311-1313.

54. Goudenège, D., Labreuche, Y., Krin, E., Ansquer, D., Mangenot, S., Calteau, A., Médigue, C., Mazel, D., Polz, M.F. \& Le Roux, F. (2013) Comparative genomics of pathogenic lineages of Vibrio nigripulchritudo identifies virulence-associated traits. ISME J. 7(10):1985-96.

55. Desriac, F., Le Chevalier, P., Brillet, B., Leguerinel, I., Thuillier, B., Paillard, C. \& Fleury, Y. (2014) Exploring the hologenome concept in marine bivalvia: haemolymph microbiota as a pertinent source of probiotics for aquaculture. FEMS Microbiol Lett. 350(1):107-16.

56. Lokmer A \& Mathias Wegner K. (2015) Hemolymph microbiome of Pacific oysters in response to temperature, temperature stress and infection. ISME J. 9(3):670-82.

57. Gay, M., Renault, T., Pons, A.M. \& Le Roux, F. (2004) Two vibrio splendidus related strains collaborate to kill Crassostrea gigas: taxonomy and host alterations. Dis Aquat Organ. 62(1-2):65-74.

58. Cordero, O.X., Wildschutte, H., Kirkup, B., Proehl, S., Ngo, L., Hussain, F., Le Roux, F., Mincer, T., Polz, M.F. (2012) Ecological populations of bacteria act as socially cohesive units of antibiotic production and resistance. Science. 337(6099): 1228-31.

59. Bassler, B.L. (2002) Small talk. Cell-to-cell communication in bacteria. Cell 109: 421424. 
Figure 1: Vibrio nigripulchritudo is an emerging pathogen of farmed shrimp in New Caledonia and other regions in the Indo-Pacific. Molecular epidemiological studies have suggested that pathogenicity is linked to particular lineages (A, B and $M)$. The pathogenicity has been assessed using 3 experimental models: shrimp transiently immersed into bacteriacontaminated waters, shrimp intramuscularly injected with bacteria, and shrimp intramuscularly injected with bacterial culture supernatants, and yielded the distinction between Highly, Moderately and Non pathogenic strain (HP in red, MP in orange and NP in green). Each contemporary lineage is comprised of nearly identical strains but comparative genomics allowed differentiation of genetic elements specific to shrimp pathogenesis of varying severity (Goudenège et al., 2014). In clade A, the highly pathogenic phenotype coincides with the presence of two plasmids pB1067 (11 kbp) and pA1066 (240kbp). The role of each replicon was investigating genetically using plasmid cured HP derivatives. In the immersion model, only strains containing both pA1066 and pB1067 were virulent, while in bacterial injection model, the wild type strain which contains both plasmids, was more virulent than a strain containing pA1066 alone. When supernatants were injected, toxicity was independent of the presence of pB1067. Collectively, these findings suggest that there may be interactions between factors encoded on the two plasmids. It is likely that differences between results obtained with the models reflect the different host-imposed barriers that are encountered by the bacteria. They may also indicate that there are multiple pathways by which the bacterium impairs shrimp viability (Le Roux et al., 2011; Goudenège et al., 2013).

EPIDEMIOLOGY
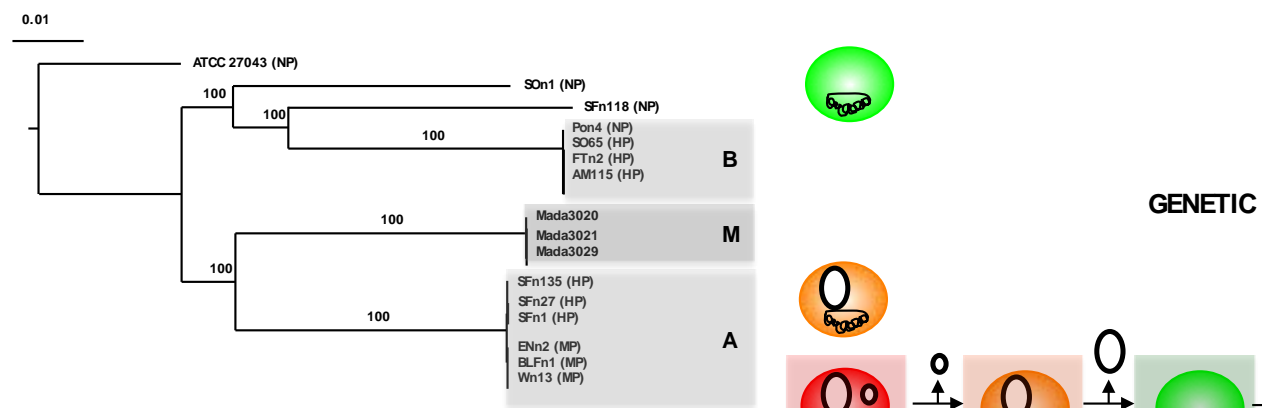

EXPERIMENTAL MODELS

Shrimp immersed into bacteria-contaminated waters

Shrimp injected with bacteria

Shrimp injected with bacterial culture supernatants

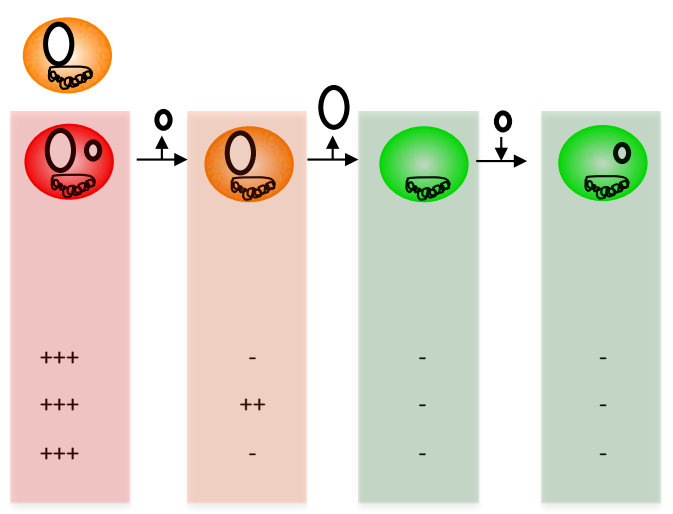


Figure 2: GFP labeled Vibrio to investigate interactions with the host at both organismal (A) and cellular levels (B). A-Artemia fransciscana was immersed into GFP labeled Vibrio sp. contaminated waters, fluorescence is visible by transparency in the animal alive. B- Hemocyte invasion by $V$. crassostreae strain J2-9. GFP-expressing J2-9 in hemocytes stained with Dapi, and rhodamin-coupled phalloidin (Courtezy from Guillaume Charrière).

A

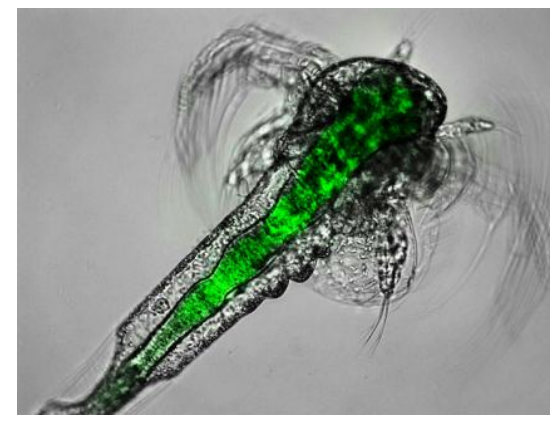

B

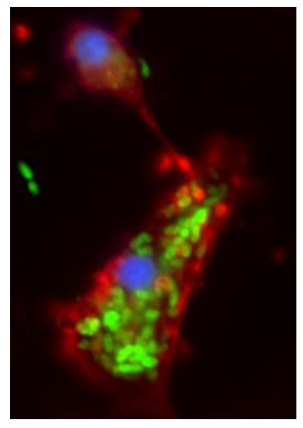


Figure 3: The different functional units of pathogenesis found in Vibrio. Pathogenic and non pathogenic strains are indicated in red and green respectively.

Population

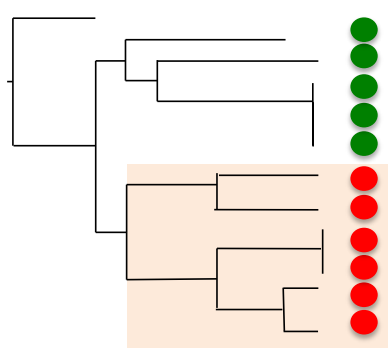

Lineage

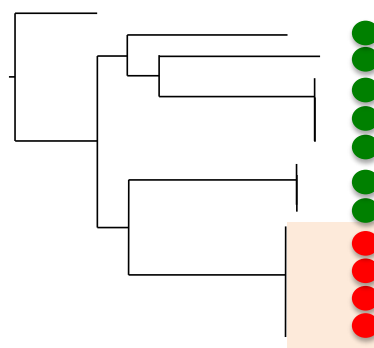

Strain

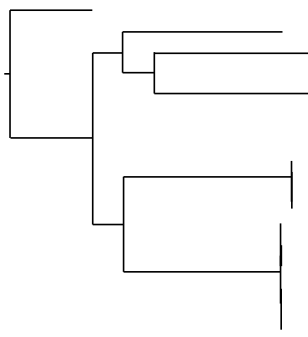

